\title{
Difficulty Accessing Syringes Mediates the Relationship Between Methamphetamine Use and Syringe Sharing Among Young Injection Drug Users
}

\author{
Brandon D. L. Marshall • Jean A. Shoveller • \\ Evan Wood • Thomas L. Patterson • \\ Thomas Kerr
}

Published online: 1 January 2011

(C) The Author(s) 2010. This article is published with open access at Springerlink.com

\begin{abstract}
Injection drug users (IDU) who use methamphetamine (MA) are at an increased risk of HIV infection due to engagement in injection-related risk behavior including syringe sharing. In this cohort study of young IDU aged 18-30, we investigated the relationship between injection MA use and syringe sharing, and whether difficulty accessing sterile syringes mediated this association. Behavioral questionnaires were completed by 384 IDU in Vancouver, Canada between October 2005 and May 2008. Generalized estimating equations were used to estimate direct and indirect effects. The median age of participants was 24 (IQR: 22-27) and 214 (55.7\%) were male. Injecting MA was independently associated with syringe sharing. Mediation analyses revealed that difficulty accessing sterile syringes partially mediated the association between injecting MA and syringe sharing. Interventions to reduce syringe sharing among young methamphetamine injectors
\end{abstract}

B. D. L. Marshall · E. Wood · T. L. Patterson · T. Kerr ( $₫)$ Urban Health Research Initiative, British Columbia Centre for Excellence in HIV/AIDS, St. Paul's Hospital, 608-1081 Burrard Street, Vancouver, BC V6Z 1Y6, Canada e-mail: uhri-tk@cfenet.ubc.ca

B. D. L. Marshall · J. A. Shoveller

School of Population and Public Health, University of British Columbia, 2206 East Mall, Vancouver, BC V6T 1Z3, Canada

E. Wood · T. Kerr

Department of Medicine, University of British Columbia, St. Paul's Hospital, 608-1081 Burrard Street, Vancouver, BC V6Z 1Y6, Canada

T. L. Patterson

Department of Psychiatry, University of California, 9500 Gilman Drive, La Jolla, CA 92093-0680, USA must address social and structural barriers to accessing HIV prevention programs.

Keywords Methamphetamine $\cdot$ HIV $\cdot$ Mediation · Injection drug use · Youth

\section{Introduction}

The sharing of non-sterile injecting equipment remains an important risk factor for HIV acquisition and other bloodborne diseases, despite impressive declines in injectingrelated risk behavior observed among injection drug users (IDU) in several settings [1-3]. Substantial evidence exists to suggest that needle and syringe exchange programs (SEPs) have played an important role in reducing HIV risk behavior and HIV seroconversion among IDU who use these programs [4, 5]. However, recent studies have raised concerns that a high prevalence of injection risk (including receptive and distributive syringe sharing) persists among new injectors and young IDU $[6,7]$. Younger injectors are less likely than adults to use SEPs, and those who do access these services use them infrequently [8,9]. Furthermore, young IDU are less likely to return to SEPs after an initial visit, with geographic proximity being a particularly important predictor of retention [10]. Research that identifies the evolving risk factors for syringe sharing among young IDU and their barriers to accessing HIV prevention programs is therefore required to inform more effective interventions to reduce the risk of blood-borne disease acquisition among this population.

The use of methamphetamine (MA) via injection among adults has been associated with a variety of adverse health and social consequences, including elevated rates of mortality in some settings $[11,12]$. Behavioral studies have 
also shown that adult MA injectors are more likely to report sexual- and injection-related risk behavior compared to other injectors [13-15]. Although much less research has examined the health and behavioral consequences of MA injection among youth, a recent systematic review concluded that young MA injectors (compared to other drug users) experience an increased risk of psychopathology and drug-related harms including overdose [16].

The primary hypothesis of the present analysis was that young people who inject MA would be more likely to report syringe sharing as compared to young IDU who inject other substances. Drawing on a growing literature demonstrating that social and structural barriers to accessing SEPs are important drivers of HIV risk behavior among IDU populations [17-19], we also hypothesized that reporting difficulty accessing sterile syringes would mediate the association between MA injection and syringe sharing. These findings may inform the development of more effective behavioral and public health interventions aiming to reduce syringe sharing and resultant infectious disease transmission among young MA injecting populations.

\section{Methods}

\section{Study Design}

Data for these analyses were derived from three prospective cohort studies that compromise a larger program of research examining the initiation and natural history of injection drug use. All cohorts are based in Vancouver, Canada and are operated by the British Columbia Centre for Excellence in HIV/AIDS. Recruitment procedures from each of the three cohorts are similar, with the primary modes of enrolment being self-referral, street outreach, and word of mouth. To be eligible for inclusion, all participants must be living in the Greater Vancouver area, greater than 14 years of age at study entry, and provide informed consent.

Although detailed sampling and recruitment procedures have been published elsewhere [20-22], each study is briefly described here. The At Risk Youth Study (ARYS) is a cohort of street-involved youth; thus, to be eligible, participants must have been between the age of 14 and 26 at enrolment. All individuals must also had used illicit drugs other than other in addition to marijuana in the past 30 days, with approximately $40 \%$ reporting a history of injection drug use at their baseline visit [23]. The Vancouver Injection Drug Users Study (VIDUS) is an open prospective cohort of HIV-negative adult IDU. All VIDUS participants must have injected an illicit drug in the past 6 months at the date of enrolment to be eligible for inclusion. The AIDS Care Cohort to Evaluate Exposure to Survival Services (ACCESS) is a cohort of HIV-positive drug users, who, similar to those in ARYS, must have recently used an illicit drug other than or in addition to marijuana to be eligible to participate.

At baseline and semi-annually, participants complete a detailed interviewer-administered questionnaire. The survey for ARYS, VIDUS, and ACCESS consists of a uniform set of questions, which permits the aggregation of data across all three cohorts. Study-specific information (e.g., injection drug use initiation in ARYS, HIV clinical care experiences in ACCESS) are also collected but were not used in this analysis. Nurses obtain blood specimens for HIV and hepatitis C serology, provide basic medial services, and offer referrals to appropriate health care services including addiction treatment. All studies have been approved by the University of British Columbia/Providence Health Care Research Ethics Board.

\section{Participants}

Data from all three cohorts were combined to achieve sufficient power to examine the predictors of syringe sharing among young participants who reported active injection drug use. All individuals who completed a baseline survey between October 2005 and May 2008 were eligible for inclusion. Thus, data used from each cohort was collected during the same time frame. For this study, individuals less than 30 years of age at enrolment were eligible for inclusion. The sample was also restricted to active IDU (i.e., participants who reported injecting at least once in the 6 months prior to the baseline interview or one of four follow-ups during the study period).

\section{Measures}

All variables examined in these analyses were assessed consistently and equivalently across the three cohorts. The dependent variable in this analysis was syringe sharing (yes versus no), defined as answering affirmatively to either, "In the past six months, have you fixed with a rig that had already been used by someone else?" or "In the past six months, have you lent your used rig to someone else?" The purchase or sale of syringes was not considered in the outcome definition since in our instrument these events refer explicitly to sterile products; therefore, the risk of HIV transmission associated with this activity is low. The primary independent variable of interest was injecting MA (either alone or in combination with other drugs) at least once in the 6 months prior to the interview (yes versus no). The potential mediator assessed in this study was "difficulty accessing sterile syringes", which was assessed by 
examining responses to the question, "Do you find it hard to get new rigs when you need them?" Participants who answered "yes" or "sometimes" were coded as having difficulty accessing syringes versus those who reported "no".

The following covariates were assessed as potential confounders: age $(<24$ versus $\geq 24)$, sex (male versus female), ethnicity (Caucasian versus other), current relationship status (single/dating versus married/regular partner), baseline HIV status (positive versus negative), and homelessness (yes versus no). These variables have been shown in previous studies to be important risk factors for MA injection or syringe sharing [7, 13, 24-27] and thus may confound the relationship between these two factors. Finally, the number of years participants reported injecting, non-injection MA use, crack use, injection cocaine use, and injection heroin use were also examined in order to compare the drug use patterns between MA injectors and noninjectors.

\section{Statistical Analysis}

As a preliminary analysis, the characteristics of those who did and did not report injecting MA at baseline were compared using Pearson's chi-square test for dichotomous variables and the Kruskal-Wallis test for continuous variables. We then conducted a series of longitudinal analyses to determine the independent association between MA injection and syringe sharing over the study period. We used a generalized estimating equation (GEE) approach with logit link for binary outcomes since the factors associated with syringe sharing, including the primary independent variable of interest and many potential confounders were serial (i.e., time-dependent) measures. Since GEE account for the correlation between repeated measures for each subject, valid estimates of association and standard errors are obtained [28]. Furthermore, these methods permitted the inclusion of all data collected in any survey during which active injection drug use was reported (i.e., participants did not need to report injecting drugs over the entire study period to be eligible).

In order to identify potential confounders in the relationship between MA injection and syringe sharing, we used an approach first described by Hosmer and Lemeshow [29]. We first computed the estimate of association between the outcome and the primary explanatory variable of interest, and then assessed whether the addition of each potentially confounding covariate resulted in a relative change of this coefficient by more than $\pm 10 \%$. All variables that achieved this a priori-defined cut-off were considered confounders and thus included in all subsequent regressions (see below).
As a next step, a mediation analysis was conducted according to the procedures recommended by Baron and Kenny [30]. Mediation analysis permits the examination of potential mechanisms through which independent variables (e.g., MA injection) impact health behaviors (e.g., syringe sharing). Three multivariate longitudinal regressions were conducted to determine the relationship between: (1) path $a$, the independent variable (i.e., injecting MA) and the mediator (i.e., difficulty accessing syringes); (2) path $b$, the mediator and the dependent variable (i.e., syringe sharing), adjusting for the effect of the independent variable; and (3) path $c$, the independent variable and the dependent variable. To determine the extent to which difficulty accessing syringes mediated the association between injecting MA and syringe sharing, a final model with both the mediator and independent variable as predictors of the dependent variable was conducted to estimate coefficient $c^{\prime}$. If mediation is present, the magnitude and significance of $c^{\prime}$ should be less than $c$. In the case that the relationship is explained entirely by the mediated pathway (i.e., full mediation), $c^{\prime}$ should equal zero. If the coefficient remains positive, partial mediation is present, which indicates that although the mediator may be important, it does not fully account for the relationship between the dependent and independent variables. Finally, to determine the statistical significance of the proposed mediation pathway, a Sobel test was conducted [31]. This test is used to determine whether the indirect effect of the independent variable on the dependent variable via the mediator is significantly different from zero.

We recognized that the primary exposure (i.e., any MA injection in the past 6 months) was very broadly defined, and as such may not represent individuals who primarily or very frequently inject MA. Therefore, as a sensitivity analysis, we examined whether a more stringently-defined independent variable also predicted higher rates of syringe sharing and difficulty accessing sterile syringes. The mediation analyses described above were thus repeated, using as a primary explanatory variable frequent (i.e., at least daily) versus non-frequent (i.e., less than daily) MA injection in the past 6 months. All statistical analyses were conducted using SAS version 9.1.3 (SAS Institute Inc., Cary, NC) and all $P$-values are two-sided.

\section{Results}

\section{Descriptive Statistics}

Among 756 young participants recruited, 384 (50.8\%) reported injecting over the study period and were thus eligible for inclusion in this analysis. The median age of eligible respondents was 24.2 [interquartile range (IQR): 
22.0-26.8], 214 (55.7\%) were male, and 244 (63.5\%) were of Caucasian ethnicity. At baseline, 187 (48.7\%) reported injecting MA at least once in the past 6 months; of these, $56(30.0 \%)$ reported doing as at least daily. The median number of years participants reported injecting was 7 (IQR: 4-10). Other sociodemographic, behavioral, and drug use information stratified by baseline self-reported MA injection is reported in Table 1.
Bivariate Analyses

Several significant differences between MA injectors and non-MA injectors were observed. The former group reported significantly fewer years injecting: six versus eight, respectively $\left(\chi^{2}=11.0, d f=1, P=0.001\right)$. As shown in Table 1, MA injectors were more likely to be less than 24 years of age (53.8 vs. $41.4 \%, P=0.016)$, male

Table 1 Baseline characteristics of young IDU, stratified by self-reported methamphetamine (MA) injection $(n=384)$

\begin{tabular}{|c|c|c|c|c|}
\hline Characteristic & $\begin{array}{l}\text { Inject } \mathrm{MA}^{\mathrm{a}} \\
(n=187)(N, \%)\end{array}$ & $\begin{array}{l}\text { Did not inject } \mathrm{MA}^{\mathrm{a}} \\
(n=197)(N, \%)\end{array}$ & OR $(95 \% \mathrm{CI})$ & $P$-value \\
\hline \multicolumn{5}{|l|}{ Age } \\
\hline$<24$ & $99(53.8)$ & $79(41.4)$ & \multirow[t]{2}{*}{$1.64(1.10-2.50)$} & \multirow[t]{2}{*}{0.016} \\
\hline$\geq 24$ & $85(46.2)$ & $112(58.6)$ & & \\
\hline \multicolumn{5}{|l|}{ Sex } \\
\hline Male & $116(62.7)$ & $98(51.0)$ & \multirow[t]{2}{*}{$1.61(1.06-2.44)$} & \multirow[t]{2}{*}{0.023} \\
\hline Female & $69(37.3)$ & $94(49.0)$ & & \\
\hline \multicolumn{5}{|l|}{ Ethnicity } \\
\hline Caucasian & 133 (71.9) & $111(57.8)$ & \multirow[t]{2}{*}{$1.87(1.21-2.87)$} & \multirow[t]{2}{*}{0.004} \\
\hline Other & $52(28.1)$ & $81(42.2)$ & & \\
\hline \multicolumn{5}{|l|}{ Relationship status } \\
\hline Single/dating & $142(75.9)$ & $126(65.0)$ & \multirow[t]{2}{*}{$1.70(1.09-2.66)$} & \multirow[t]{2}{*}{0.020} \\
\hline Married/regular partner & $45(24.1)$ & $68(35.0)$ & & \\
\hline \multicolumn{5}{|l|}{ HIV status } \\
\hline Positive & $20(10.8)$ & $29(15.1)$ & \multirow[t]{2}{*}{$0.68(0.37-1.25)$} & \multirow[t]{2}{*}{0.217} \\
\hline Negative & $165(89.2)$ & $163(84.9)$ & & \\
\hline \multicolumn{5}{|l|}{ Homeless $^{\mathrm{a}}$} \\
\hline Yes & 119 (63.6) & $114(57.9)$ & \multirow[t]{2}{*}{$1.27(0.84-1.92)$} & \multirow[t]{2}{*}{0.247} \\
\hline No & $68(36.4)$ & $83(55.0)$ & & \\
\hline \multicolumn{5}{|l|}{ Non-injection MA use ${ }^{\mathrm{a}}$} \\
\hline Yes & $110(59.5)$ & $22(11.2)$ & \multirow[t]{2}{*}{$11.60(6.81-19.74)$} & \multirow[t]{2}{*}{$<0.001$} \\
\hline No & $75(40.5)$ & $174(88.8)$ & & \\
\hline \multicolumn{5}{|l|}{ Crack use $^{\mathrm{a}}$} \\
\hline Yes & $126(67.4)$ & $151(77.0)$ & \multirow[t]{2}{*}{$0.62(0.39-0.97)$} & \multirow[t]{2}{*}{0.035} \\
\hline No & $61(32.6)$ & $45(23.0)$ & & \\
\hline \multicolumn{5}{|l|}{ Injection cocaine $u^{a} e^{a}$} \\
\hline Yes & $56(30.6)$ & $82(42.3)$ & \multirow[t]{2}{*}{$0.60(0.39-0.92)$} & \multirow[t]{2}{*}{0.019} \\
\hline No & $127(69.4)$ & $112(57.7)$ & & \\
\hline \multicolumn{5}{|l|}{ Injection heroin use ${ }^{\mathrm{a}}$} \\
\hline Yes & $111(61.3)$ & $157(80.1)$ & $0.39(0.25-0.63)$ & $<0.001$ \\
\hline No & $70(38.7)$ & 39 (19.9) & & \\
\hline Syringe sharing ${ }^{\mathrm{a}}$ & & & & \\
\hline Yes & $47(25.3)$ & $29(14.7)$ & $1.96(1.17-3.28)$ & 0.010 \\
\hline No & $139(74.7)$ & $168(85.3)$ & & \\
\hline Difficulty accessing syrin & & & & \\
\hline Yes & $89(50.9)$ & $56(30.9)$ & $2.31(1.50-3.56)$ & 0.008 \\
\hline No & $86(49.1)$ & $125(69.1)$ & & \\
\hline
\end{tabular}

Note: Not all cells add to $100 \%$ due to missing values

${ }^{a}$ During the 6 months prior to the date of the first interview during which injection drug use was reported over the study period 
(62.7 vs. $51.0 \%, P=0.023$ ), Caucasian (71.9 vs. $57.8 \%$, $P=0.004)$, and single or casually dating (75.9 vs. $65.0 \%$, $P=0.020)$. Drug use patterns also varied significantly between the two groups, with MA injectors more likely to report non-injection MA use $(59.5$ vs. $11.2 \%, P<0.001)$, but less likely to report crack use, injection cocaine use, and injection heroin use (see Table 1). At baseline, syringe sharing (25.3 vs. $14.7 \%, P=0.010)$ and having difficulty accessing sterile syringes (50.9 vs. $30.9 \%, P=0.008)$ were significantly more common among participants who injected MA.

\section{Longitudinal and Mediation Analyses}

The results of the mediation analyses are shown in Fig. 1. In longitudinal analysis, MA injection was found to be significantly associated with syringe sharing $[c=0.49$, odds ratio $(\mathrm{OR})=1.63, P=0.017]$. In a series of $\mathrm{GEE}$ models examining the effect of potential confounders, only relationship status was found to change the estimate between MA injection and syringe sharing by greater than $\pm 10 \%$ [relative change $=+10.2 \%, c=0.54$, adjusted odds ratio $(\mathrm{AOR})=1.73, P=0.008]$. Thus, relationship status was controlled for in all subsequent regressions. As shown in Fig. 1, MA injectors were more likely to report having difficulty accessing syringes $(a=0.89$, AOR $=$ 2.43, $P<0.001)$. When MA injection and relationship status were controlled for, difficulty accessing syringes was positively associated with syringe sharing $(b=0.45$, AOR $=1.56, P=0.026$ ). After controlling for difficulty accessing syringes, the coefficient for MA injection lost significance and decreased in magnitude $\left(c^{\prime}=0.40\right.$, AOR $=1.49, P=0.067)$, indicating partial mediation. A Sobel test to examine the indirect effect of difficulty accessing syringes on the relationship between injecting

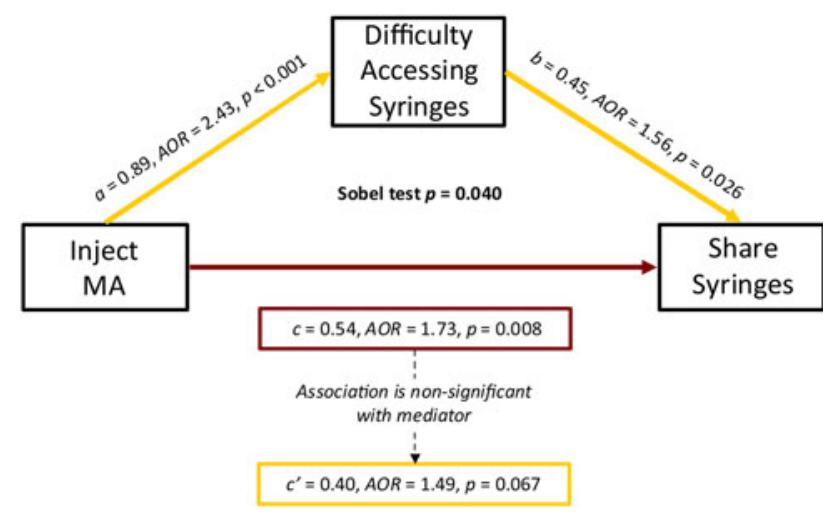

Fig. 1 Mediation analysis of the direct and indirect effects of injection methamphetamine (MA) use on syringe sharing among young IDU $(n=384)$. Note: All models are adjusted for relationship status
MA and syringe sharing confirmed the significance of the mediation pathway $(P=0.040)$.

A sensitivity analysis demonstrated that frequent (i.e., at least daily) MA injectors were significantly more likely to report syringe sharing $(\mathrm{AOR}=2.60, P<0.001)$ and difficulty accessing sterile syringes $(\mathrm{AOR}=2.19, P<0.001)$ over the study period. Consistent with the results of the primary analysis, having difficulty accessing syringes partially mediated the association between frequent MA injection and syringe sharing (Sobel test $P$-value $=0.053$ ).

\section{Discussion}

Consistent with previous studies [13, 15, 32], we observed a positive and significant association between MA injection and syringe sharing among a cohort of young injection drug users. Furthermore, participants who injected MA were over twice as likely to report having difficulty accessing sterile syringes compared to other active IDU. In a series of longitudinal regression analyses, the relationship between MA injection and syringe sharing was shown to be partially mediated by difficulty accessing syringes. These results suggest that the high prevalence of injecting-related risk behavior observed among young IDU may be driven by ongoing social and structural barriers to accessing HIV prevention programs, and that MA injectors experience particularly elevated exposure to infectious disease risk.

Previous studies have demonstrated that reporting difficulty accessing sterile syringes has historically been one of the primary risk factors for syringe sharing, even in the presence of well-established syringe exchange programmes $[17,33]$. In Vancouver, programmatic barriers, including limited hours of operation, restrictive (i.e., one-for-one) exchange policies, and travel distance are among the most common reasons for having difficulty accessing these services [33, 34]. In response to these concerns, the local health authority began a series of SEP policy reforms in 2000, including: a shift to syringe distribution and recovery instead of one-for-one exchange; decentralizing services to expand the number of sites distributing supplies; and diversifying the delivery of these services to include fixedsite programs, outreach, foot patrols, peer-run programs, and the distribution of supplies at all local health clinics and pharmacies. These policy changes have recently been shown to have resulted in large reductions in syringe sharing among IDU and have contributed to declining HIV incidence [1].

Our results suggest that young MA injectors continue to report having difficulty accessing sterile syringes, even in an era of high coverage, widespread syringe distribution. Further research will be required to determine the most common individual, social, and structural barriers 
experienced by young people who inject MA, although existing studies suggest that some of the factors previously reported by adult IDU continue to affect this population's access to HIV prevention interventions [8, 10]. For example, since geographic proximity to SEPs is an important predictor of programme utilization and risk behavior [34, 35], it is possible that many MA injectors either are not in close proximity to SEPs or avoid areas where they are located. Ethnographic work in our setting has shown how youth perceive neighbourhoods with extensive open drug scenes (and thus a concentration of SEPs) as being environments of exceptional danger and actively seek to avoid it [36]. Furthermore, MA injectors may feel uncomfortable or unwelcome accessing HIV prevention programs that cater largely to opioid users [37]. For these reasons, future SEP expansion and development should consider the perspectives of young MA injectors to determine how these programmes can be accessed more safely, including for example locating services in areas frequented by young MA-using IDU and adopting peerbased staffing models.

While structural barriers clearly contribute to ones' (in)ability to access HIV prevention services, other individual factors and social influences may be operating to prevent MA injectors from obtaining sterile syringes. For example, MA users may have difficulty accessing safer injecting equipment while on multi-day drug "binges" or during periods of MA-induced psychological distress [38]. Prior research has also shown that MA injectors (compared to heroin users) are more likely to inject in groups or with friends, which may promote the sharing of syringes and other injecting equipment [39]. Future research will be required to identify at what level barriers to service access are operating, and how individual, social, and structural barriers intersect to produce HIV-related harms.

The results of this study have a number of important implications for future interventions that seek to address injection-related risk behavior among young MA injectors. Given that MA users are more likely to experience barriers while attempting to access harm reduction and HIV prevention services, interventions and policies that promote secondary syringe distribution (i.e., receiving supplies from peers who access SEPs) are recommended. Youth-driven models of syringe distribution, including fixed and outreach-based services run by or catered specifically to youth, have also been shown to be successful in numerous settings [40, 41]. Given the effectiveness of supervised injecting facilities (SIFs) at reducing syringe sharing among hard-toreach and hidden populations [26], the development of youth-friendly SIFs that are acceptable to individuals injecting MA should also be considered. Furthermore, interventions that harness social influence and promote positive peer norms among MA-using IDU networks may be effective at reducing risk behavior and encouraging uptake of HIV prevention and other health services [42]. Efforts must be made to develop effective HIV prevention strategies tailored specifically to MA injectors, given the unique injecting practices and health issues experienced by this population [43]. Finally, future research in this area may benefit from the incorporation of novel methodologies [including for example geographic information systems (GIS)] to determine the geographic distribution and coverage of services that would most effectively meet the needs of this vulnerable IDU subpopulation. For example, a recent study in New York City used GIS methodology to demonstrate substantial cross-neighbourhood variation in SEP access [44], although it remains to be determined whether specific subgroups of injectors (including young IDU and MA users) are disproportionately affected by the inequitable geographic distribution of services in this setting.

When drawing conclusions from this study, several limitations should be noted. The ARYS, VIDUS, and ACCESS cohorts are not random samples of the populations they seek to represent; therefore, generalizability to the larger drugusing community or other settings may be limited. We note however that the sociodemographic characteristics of these samples are similar to other street youth and injection drugusing studies that have been conducted in Canada [45, 46]. A second limitation is that all behaviors assessed in this study were self-reported, and it is possible that stigmatized behaviors including syringe sharing may have been underreported. However, we have no reason to believe the magnitude of this bias would differ between MA injectors and non-injectors; therefore, if present, socially desirable reporting would attenuate our results towards the null. We note also that previous studies have shown young peoples' self-reports to be reliable measures of drug use and other HIV risk behaviors [47, 48]. Finally, although the statistical methods used in these analyses preclude inference regarding causality, the longitudinal nature of the analysis suggests that the observed relationships were stable over time. Longerterm studies are required to determine whether improvements in syringe access mitigate injection risk behaviors among young people who inject MA.

Young MA injectors continue to be at an increased risk of syringe sharing, even in the presence of well-established, high coverage syringe distribution programmes. A series of meditational analyses revealed that having difficulty accessing sterile syringes is frequently reported by young MAusing IDU, and that these barriers largely accounted for the relationship between injecting MA and syringe sharing. Novel, youth-driven interventions, including the expansion of current services to adequately meet the needs of this population, are required to reduce blood-borne disease transmission among young people who inject methamphetamine. 
Acknowledgments The authors thank the study participants for their contribution to the research, as well as current and past investigators and staff. We would specifically like to thank Dr. Jane Buxton, Deborah Graham, Peter Vann, Caitlin Johnston, Steve Kain, and Calvin Lai for their research and administrative assistance. The ARYS study was supported by the US National Institutes of Health (NIH) grant R01-DA028532 as well as the Canadian Institutes of Health Research (CIHR) grant MOP-102742. The VIDUS study was supported by NIH (R01-DA011591). The ACCESS study was supported by NIH (R01-DA021525) and CIHR (MOP-79297). All studies are supported by a CIHR team grant RAA-79918. Thomas Kerr is supported by the Michael Smith Foundation for Health Research (MSFHR) and the CIHR. Brandon Marshall is supported by senior graduate trainee awards from MSFHR and CIHR.

Open Access This article is distributed under the terms of the Creative Commons Attribution Noncommercial License which permits any noncommercial use, distribution, and reproduction in any medium, provided the original author(s) and source are credited.

\section{References}

1. Kerr T, Small W, Buchner C, et al. Syringe sharing and HIV incidence among injection drug users and increased access to sterile syringes. Am J Public Health. 2010;100(8):1449-53.

2. Pouget ER, Deren S, Fuller CM, et al. Receptive syringe sharing among injection drug users in Harlem and the Bronx during the New York State Expanded Syringe Access Demonstration Program. J Acquir Immune Defic Syndr. 2005;39(4):471-7.

3. Des Jarlais C, Perlis T, Friedman SR, et al. Behavioral risk reduction in a declining HIV epidemic: injection drug users in New York City, 1990-1997. Am J Public Health. 2000;90(7):1112-6.

4. Gibson DR, Flynn NM, Perales D. Effectiveness of syringe exchange programs in reducing HIV risk behavior and HIV seroconversion among injecting drug users. AIDS. 2001;15(11): 1329-41.

5. Wodak A, Cooney A. Do needle syringe programs reduce HIV infection among injecting drug users: a comprehensive review of the international evidence. Subst Use Misuse. 2006;41(6-7): 777-813.

6. Golub ET, Strathdee SA, Bailey SL, et al. Distributive syringe sharing among young adult injection drug users in five U.S. cities. Drug Alcohol Depend. 2007;91(Suppl 1):S30-8.

7. Lloyd-Smith E, Kerr T, Zhang R, Montaner JSG, Wood E. High prevalence of syringe sharing among street involved youth. Addict Res Theory. 2008;16(4):353-8.

8. Bailey SL, Huo D, Garfein RS, Ouellet LJ. The use of needle exchange by young injection drug users. J Acquir Immune Defic Syndr. 2003;34(1):67-70.

9. Sherman SG, Rusch M, Golub ET. Correlates of safe syringe acquisition and disposal practices among young IDUs: broadening our notion of risk. J Drug Issues. 2004;34(4):895-911.

10. Gindi RM, Rucker MG, Serio-Chapman CE, Sherman SG. Utilization patterns and correlates of retention among clients of the needle exchange program in Baltimore, Maryland. Drug Alcohol Depend. 2009;103(3):93-8.

11. Darke S, Kaye S, McKetin R, Duflou J. Major physical and psychological harms of methamphetamine use. Drug Alcohol Rev. 2008;27(3):253-62.

12. Singleton J, Degenhardt L, Hall W, Zabransky T. Mortality among amphetamine users: a systematic review of cohort studies. Drug Alcohol Depend. 2009;105(1-2):1-8.
13. Fairbairn N, Kerr T, Buxton JA, Li K, Montaner JS, Wood E. Increasing use and associated harms of crystal methamphetamine injection in a Canadian setting. Drug Alcohol Depend. 2007; 88(2-3):313-6.

14. Molitor F, Ruiz JD, Flynn N, Mikanda JN, Sun RK, Anderson R. Methamphetamine use and sexual and injection risk behaviors among out-of-treatment injection drug users. Am J Drug Alcohol Abuse. 1999;25(3):475-93.

15. Lorvick J, Martinez A, Gee L, Kral AH. Sexual and injection risk among women who inject methamphetamine in San Francisco. J Urban Health. 2006;83(3):497-505.

16. Marshall BDL, Werb D. Health outcomes associated with methamphetamine use among young people: a systematic review. Addiction. 2010;105(6):991-1002.

17. Wood E, Tyndall MW, Spittal PM, et al. Factors associated with persistent high-risk syringe sharing in the presence of an established needle exchange programme. AIDS. 2002;16(6):941-3.

18. Taussig JA, Weinstein B, Burris S, Jones TS. Syringe laws and pharmacy regulations are structural constraints on HIV prevention in the US. AIDS. 2000;14(Suppl 1):S47-51.

19. Finlinson HA, Oliver-Vélez D, Colón HM, et al. Syringe acquisition and use of syringe exchange programs by Puerto Rican drug injectors in New York and Puerto Rico: comparisons based on quantitative and qualitative methods. AIDS Behav. 2000;4(4): 341-51.

20. Tyndall MW, Currie $S$, Spittal $P$, et al. Intensive injection cocaine use as the primary risk factor in the Vancouver HIV-1 epidemic. AIDS. 2003;17(6):887-93.

21. Strathdee SA, Palepu A, Cornelisse PG, et al. Barriers to use of free antiretroviral therapy in injection drug users. JAMA. 1998; 280(6):547-9.

22. Wood E, Stoltz JA, Montaner JS, Kerr T. Evaluating methamphetamine use and risks of injection initiation among street youth: the ARYS study. Harm Reduct J. 2006;3:18.

23. Kerr T, Marshall BDL, Miller C, et al. Injection drug use among street-involved youth in a Canadian setting. BMC Public Health. 2009;9:171.

24. Wood E, Montaner JS, Li K, et al. Burden of HIV infection among Aboriginal injection drug users in Vancouver, British Columbia. Am J Public Health. 2008;98(3):515-9.

25. Sherman SG, Latkin CA, Gielen AC. Social factors related to syringe sharing among injecting partners: a focus on gender. Subst Use Misuse. 2001;36(14):2113-36.

26. Kerr T, Tyndall M, Li K, Montaner J, Wood E. Safer injection facility use and syringe sharing in injection drug users. Lancet. 2005;366(9482):316-8.

27. Gu J, Wang $\mathrm{R}$, Chen $\mathrm{H}$, et al. Prevalence of needle sharing, commercial sex behaviors and associated factors in Chinese male and female injecting drug user populations. AIDS Care. 2009; 21(1):31-41.

28. Liang KY, Zeger SL. Longitudinal data analysis using generalized linear models. Biometrika. 1986;73(1):13-22.

29. Hosmer DW, Lemeshow S. Applied logistic regression. 2nd ed. Hoboken, NJ: Wiley; 2000.

30. Baron RM, Kenny DA. The moderator-mediator variable distinction in social psychological research: conceptual, strategic, and statistical considerations. J Pers Soc Psychol. 1986;51(6): 1173-82.

31. Sobel ME. Asymptotic intervals for indirect effects in structural equation models. In: Leinhardt S, editor. Sociological methodology. San Francisco, CA: Jossey-Bass Publishers; 1982.

32. van Griensvan F, Keawkungwal J, Tappero JW, et al. Lack of increased HIV risk behavior among injection drug users participating in the AIDSVAX B/E HIV vaccine trial in Bangkok, Thailand. AIDS. 2004;18(2):295-301. 
33. Wood E, Tyndall MW, Spittal PM, et al. Needle exchange and difficulty with needle access during an ongoing HIV epidemic. Int J Drug Policy. 2002;13(2):95-102.

34. Rockwell R, Des Jarlais DC, Friedman SR, Perlis TE, Paone D. Geographic proximity, policy and utilization of syringe exchange programmes. AIDS Care. 1999;11(4):437-42.

35. Bruneau J, Daniel M, Kestens Y, Zang G, Genereux M. Associations between HIV-related injection behaviour and distance to and patterns of utilisation of syringe-supply programmes. J Epidemiol Community Health. 2008;62(9):804-10.

36. Fast D, Shoveller J, Shannon K, Kerr T. Safety and danger in downtown Vancouver: understandings of place among young people entrenched in an urban drug scene. Health Place. 2010;16(1):51-60.

37. Sears C, Guydish JR, Weltzien EK, Lum PJ. Investigation of a secondary syringe exchange program for homeless young adult injection drug users in San Francisco, California, U.S.A. J Acquir Immune Defic Syndr. 2001;27(2):193-201.

38. Darke S, Ross J, Cohen J, Hando J, Hall W. Injecting and sexual risk-taking behaviour among regular amphetamine users. AIDS Care. 1995;7(1):19-26.

39. Kaye S, Darke S. A comparison of the harms associated with the injection of heroin and amphetamines. Drug Alcohol Depend. 2000;58(1-2):189-95.

40. Hahn JA, Page-Shafer K, Lum PJ, Ochoa K, Moss AR. Hepatitis $\mathrm{C}$ virus infection and needle exchange use among young injection drug users in San Francisco. Hepatology. 2001;34(1): $180-7$.
41. Barrington G. Case study: YouthCO AIDS Society. Public Health Agency of Canada. http://www.phac-aspc.gc.ca/hepc/pubs/pcsrep/youthco-eng.php. Accessed August 23, 2010.

42. Sherman SG, Sutcliffe C, Srirojn B, Latkin CA, Aramratanna A, Celentano DD. Evaluation of a peer network intervention trial among young methamphetamine users in Chiang Mai, Thailand. Soc Sci Med. 2009;68(1):69-79.

43. Degenhardt L, Baker A, Maher L. Methamphetamine: geographic areas and populations at risk, and emerging evidence for effective interventions. Drug Alcohol Rev. 2008;27(3):217-9.

44. Cooper HL, Bossak B, Tempalski B, Des Jarlais DC, Friedman SR. Geographic approaches to quantifying the risk environment: drug-related law enforcement and access to syringe exchange programmes. Int J Drug Policy. 2009;20(3):217-26.

45. Roy E, Haley N, Leclerc P, et al. HIV incidence among street youth in Montreal, Canada. AIDS. 2003;17(7):1071-5.

46. Bruneau J, Lamothe F, Soto J, et al. Sex-specific determinants of HIV infection among injection drug users in Montreal. Can Med Assoc J. 2001;164(6):767-73.

47. Solbergsdottir E, Bjornsson G, Gudmundsson LS, Tyrfingsson T, Kristinsson J. Validity of self-reports and drug use among young people seeking treatment for substance abuse or dependence. J Addict Dis. 2004;23(1):29-38.

48. Shew ML, Remafedi GJ, Bearinger LH, et al. The validity of selfreported condom use among adolescents. Sex Transm Dis. 1997;24(9):503-10. 